\title{
A randomized controlled trial demonstrating sustained benefit of Autologous Matrix-Induced Chondrogenesis over microfracture at five years
}

\author{
Martin Volz $^{1}$ - Jens Schaumburger ${ }^{2}$ Hubert Frick ${ }^{1}$ - Joachim Grifka ${ }^{2}$ - Sven Anders ${ }^{2}$
}

Received: 9 August 2016 / Accepted: 26 December 2016/Published online: 20 January 2017

(C) The Author(s) 2017. This article is published with open access at Springerlink.com

\begin{abstract}
Purpose Autologous Matrix-Induced Chondrogenesis $\left(\right.$ AMIC $^{\circledR}$ ) utilizing a type I/III collagen membrane was compared with microfracture (MFx) alone in focal cartilage lesions of the knee at one, two and five years.

Methods Forty-seven patients (aged $37 \pm 10$ years, mean defect size $3.6 \pm 1.6 \mathrm{~cm}^{2}$ ) were randomized and treated either with $\mathrm{MFx}$, with sutured or glued $\mathrm{AMIC}^{\circledR}$ in a prospective multicentre clinical trial.

Results After improvement for the first two years in all subgroups, a progressive and significant score degradation was observed in the MFx group, while all functional parameters remained stable for least five years in the $\mathrm{AMIC}^{\circledR}$ groups. At two and five years, MRI defect filling was more complete in the $\mathrm{AMIC}^{\circledR}$ groups. No treatment-related adverse events were reported.

Conclusions $\mathrm{AMIC}^{\circledR}$ is an effective cartilage repair procedure in the knee resulting in stable clinical results significantly better than the MFx group at five years.
\end{abstract}

Keywords Articular cartilage $\cdot$ Autologous Matrix-Induced Chondrogenesis $\left(\right.$ AMIC $\left.^{\circledR}\right) \cdot$ Chondro-Gide ${ }^{\circledR} \cdot$ Knee surgery $\cdot$ Microfracture

Sven Anders

s.anders@asklepios.com

Sportklinik Ravensburg, Ravensburg, Germany

2 Department of Orthopedic Surgery, University of Regensburg, Asklepios Clinical Center Bad Abbach, Bad Abbach, Germany

\section{Introduction}

Cartilage has a low intrinsic regenerative and reparative capacity, and cartilage defects can potentially lead to severe osteoarthritis in the long term. A variety of surgical techniques that aim to resurface and repair the damaged articular cartilage include perforation of the subchondral bone, mosaicplasty, and autologous chondrocyte transplantation. Marrow stimulation methods, such as microfracturing (MFx), involve penetration of the subchondral bone plate to access the bone marrow compartment. The resulting blood clot enriched with bone marrow elements is thought to provide a favourable microenvironment for the development of the cartilage repair tissue. This so-called superclot is capable of further stimulating the migration, proliferation, and chondrogenic differentiation of mesenchymal stem cells from the bone marrow [1]. Currently, microfracturing as well as mosaicplasty is recommended as the treatment of choice for smaller cartilage defects $\left(<2 \mathrm{~cm}^{2}\right)[2]$, while autologous chondrocyte implantation (ACI) can be an alternative therapeutic option for larger defects [3, 4]. Reasons to improve the microfracture procedure were given by various recent reviews and studies showing unfavourable long term results, especially in larger lesions $[4,5]$. In a meta-analysis, microfracture effectively improved knee function in all studies during the first 1824 months after microfracture, but the reports on durability were conflicting [6].

In Autologous Matrix-induced Chondrogenesis $\left(\mathrm{AMIC}^{\circledR}\right)$, the microfracturing is directly followed by the application of the biodegradable natural collagen type I/III membrane Chondro-Gide ${ }^{\circledR}$ (Geistlich Pharma AG, Wolhusen, Switzerland) to host and hold the superclot generated by microfracturing [7]. The principle of the AMIC $^{\circledR}$ technique was proven in a sheep model [8]. So far, promising clinical 
results with the AMIC technique were reported by case series only $[9,10]$.

In order to investigate the mid-term clinical benefit of $\mathrm{AMIC}^{\circledR}$, a prospective, randomized controlled clinical trial (RCT) was designed to compare $\mathrm{AMIC}^{\circledR}$ to classical microfracture in knee cartilage lesions $>2 \mathrm{~cm}^{2}$, with a followup of five years. We hypothesize that adding a collagen membrane, fixed either by gluing or sutering, to the conventional microfraturing like in any $\mathrm{AMIC}^{\circledR}$ procedure would result in better clinical and morphological results in these patients.

\section{Material and methods}

\section{Study design}

A prospective, randomized, controlled trial (RCT) was designed to assess the efficacy and safety of the AMIC ${ }^{\circledR}$ technique compared to MFx alone in the treatment of small-tomedium size cartilage defects of the knee.

Patients between 18 and 50 years of age with one or two isolated cartilage defects of the knee grade III or IV according to the Outerbridge classification [11], located either on the medial or lateral femoral condyle, trochlea or patella and a defect size between 2 and $10 \mathrm{~cm}^{2}$ were enrolled in the study. Patients with more than two defects, two corresponding defects or bilateral defects were excluded, as were those with signs of osteoarthritis, bone lesions deeper than $0.7 \mathrm{~cm}$, axis deviation of more than $\pm 5^{\circ}$ in the frontal plane and unresolved knee instability. Further exclusion criteria were: rheumatoid arthritis, infectious diseases, endocrine, metabolic or autoimmune diseases, previous subtotal or total meniscus resection or mosaicplasty, treatment with cartilage specific medication (e.g., hyaluronic acid), and chondropathia patellae, patella dysplasia or patella instability. Thus, any patient with concomitant lesions of anterior cruciate ligament, meniscus or axial malalignement was excluded from enrolment in the study.

Microfracture (MFx) was applied in every patient as the basic therapy. Patients were randomly assigned to one of three study groups receiving the following treatments: microfracture alone $(\mathrm{MFx})$, sutured $\mathrm{AMIC}^{\circledR}$ or glued AMIC $^{\circledR}$ by drawing a sealed envelope. The study endpoints included clinical evaluation as well as MRI evaluation at one, two and five years follow-up. All patients provided informed written consent before arthroscopy and also agreed to comply with a strict post-operative physiotherapy program.

According to a power analysis, the study was originally planned to include 120 patients, 40 in each group. Accordingly, computer assisted block randomization was carried out in blocks of 30, explaining the variability of the patients recruited in each group. Because of the study design comparing a total arthroscopic procedure (MFx alone) with an open procedure (AMIC ${ }^{\circledR}$ glued or AMIC $^{\circledR}$ sutured) neither the patient nor the physicians were blinded.

The study was approved by the Ethics Committee (03-088 and 03/173-MZ, ZKS, University of Regensburg) and was conducted according to the declaration of Helsinki and Good Clinical Practice.

Sixty-seven patients were initially enrolled (18 MFx, 27 $\mathrm{AMIC}^{\circledR}$ glued and $22 \mathrm{AMIC}^{\circledR}$ sutured) in seven centres in Germany. Five centres with a low recruitment number $(<6$ patients) were closed after the collection of the two years follow-up. The analysis presented here includes 47 patients enrolled in two centers which reached the study endpoint at five years follow-up.

\section{Surgical procedures}

MFx was performed according to the technique published by Steadman et al. [12] as an arthroscopic procedure. For the $\mathrm{AMIC}^{\circledR}$ groups, a miniarthrotomy and microfracturing was performed, and a collagen type I/III membrane (ChondroGide $^{\circledR}$, Geistlich Pharma AG, Wolhusen, Switzerland) was added to cover the microfractured defect area. ChondroGide ${ }^{\circledR}$ was placed with the porous layer facing the bone surface and fixed either using sutures (PDS 5.0, Ethicon, Norderstedt, Germany; sutured AMIC ${ }^{\circledR}$ ) or by gluing the matrix with fibrin glue (Tissucol, Baxter, Unterschleissheim, Germany; glued AMIC ${ }^{\circledR}$ ) (Fig. 1).

\section{Post-operative rehabilitation program}

The staged rehabilitation program was standardized for all treatment groups. In brief, it included foot sole contact for six weeks using crutches building up full weight bearing after eight weeks. Range of motion was restricted to $0 / 0 / 30^{\circ}$ in defects of the patella or trochlea and $0 / 0 / 60^{\circ}$ of the femoral condyle for the first ten days post-operatively and to $0 / 0 / 90^{\circ}$ for six weeks for both groups. Mobilization exercises including continuous passive motion, electrotherapy of leg muscles and proprioception training were provided. Jogging was allowed after six months and contact sports were restricted for 18 months [13].

\section{Assessment of clinical outcome and safety}

Clinical outcome was assessed by using the Modified Cincinnati [14] and Modified ICRS [15] scores and a visual analogue scale for the subjective functional status of the knee from 0 (no pain) to 100 (severe pain). Functional status was rated from normal to severely abnormal according to the ICRS Cartilage Injury Standard Evaluation Form-2000 [15]. The function of the knee was evaluated by the surgeon utilizing parts three, four and seven of the ICRS form. Safety was evaluated by physical examination and monitoring of adverse events. 
Fig. 1 Images of the $\mathrm{AMIC}^{\circledR}$ surgical technique (right medial femoral condyle): micofracture of the debrided defect (a); subchondral bleeding after microfracture (b); imprint and trimming Chondo-Gide ${ }^{\circledR}$ membrane (c); Chondro-Gide ${ }^{\circledR}$ membrane is sutured into the defect with the porous layer facing the bone surface $(\mathbf{d})$
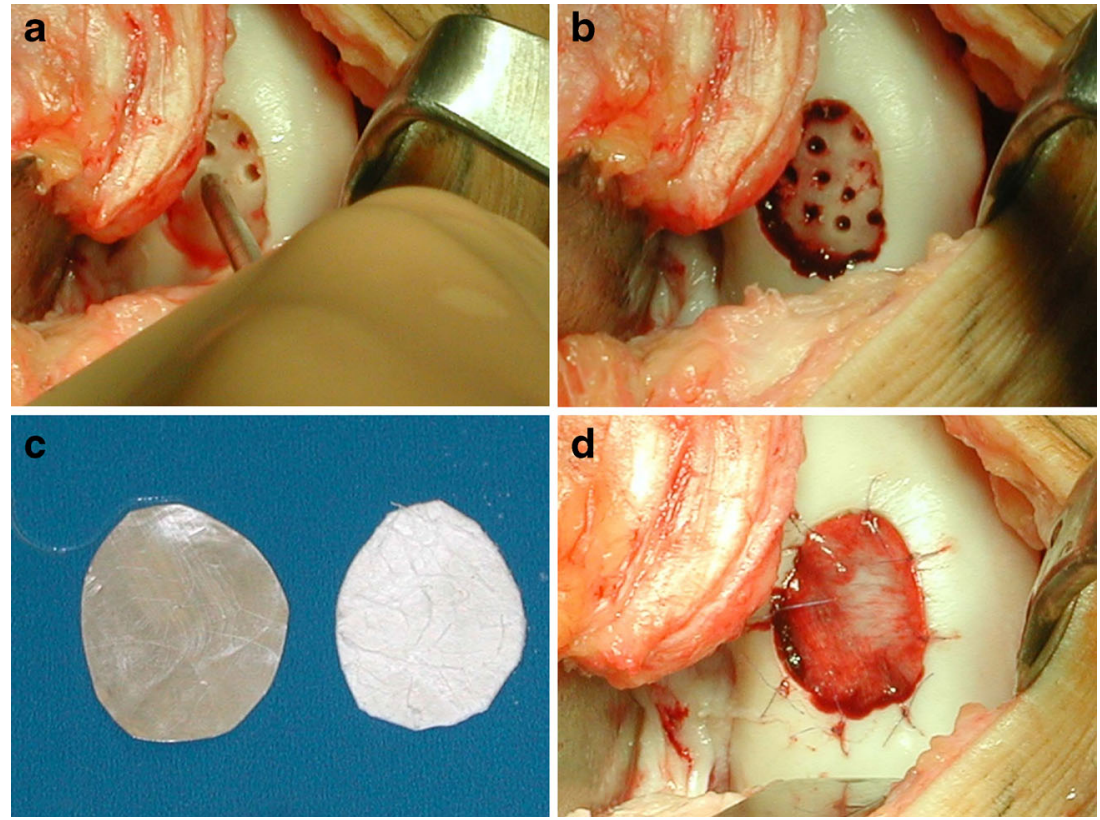

\section{MRI analysis}

Structural repair was assessed with magnetic resonance imaging (MRI, $1.5 \mathrm{~T}$ ) by an independent and blinded radiologist, with a focus on the extent, signal intensity, and surface of the defect filling, integration to adjacent cartilage, and bone marrow lesion (BML). The adapted scoring system used takes into account a variety of features that are currently believed to be relevant to the integrity of cartilage repair tissue as used in the MOCART-score [16] after ACI and semiquantitative MRI-scores of osteoarthritis established as BLOKS [17] and WORMS [18].

\section{Histological analysis of biopsies at two years}

The repair tissue was assessed by perpendicular osteochondral biopsy material from patients who have consented to the procedure, analyzed centrally by an independent and blinded pathologist. The evaluation was carried out according to the International Cartilage Repair Society (ICRS) histology score [19].

\section{Statistical analysis}

Inferential data analysis of treatment effects was performed by the Brunner-Langer-approach [20], suitable for analyzing designs of this type with the significance level of $5 \%$ is used as a threshold for hypotheses testing. For each of the endpoints listed in the next section, two questions were addressed:

1. Do the values differ systematically over time? (e.g., main effect of time)

2. Do the changes over time differ systematically between treatments? (e.g., interaction effect between treatment and time)
All statistical analyses were performed using the statistics software R version 3.0.3 [21].

\section{Results}

\section{Baseline characteristics}

Forty-seven patients were randomized and treated (13 MFx, $17 \mathrm{AMIC}^{\circledR}$ glued, $17 \mathrm{AMIC}^{\circledR}$ sutured) (Fig. 2). Mean patient age at surgery was 37 years (range 21-50) and the mean defect size after debridement was $3.6 \mathrm{~cm}^{2}$ (range 2.1-6.6 $\mathrm{cm}^{2}$ ). Lesions were mostly located on the femoral condyles and about $50 \%$ of patients had previous surgeries on the affected knee. Baseline characteristics were largely comparable between groups (Table 1).

\section{Clinical outcomes}

Mean Modified Cincinnati score (Fig. 3) increased significantly from baseline values of $38 \pm 19$ for the MFx group, $48 \pm 15$ for the glued AMIC ${ }^{\circledR}$ group and $45 \pm 19$ for the sutured $\mathrm{AMIC}^{\circledR}$ group to $72 \pm 18(p<0.001), 67 \pm 26(p=0.028)$ and $82 \pm 15(p<0.001)$, respectively, at one year post-operation.

At two years, 37 patients could be evaluated. The scores still increased in the MFx and AMIC ${ }^{\circledR}$ glued groups, to 74 \pm 26 and $85 \pm 18$, respectively, whereas a slight non-significant decrease versus 1 year values was noted in the sutured AMIC ${ }^{\circledR}$ group. The mean change from baseline to two years post-operation was comparable.

After five years, 39 patients could be evaluated. The Modified Cincinnati score was at least stable or even 


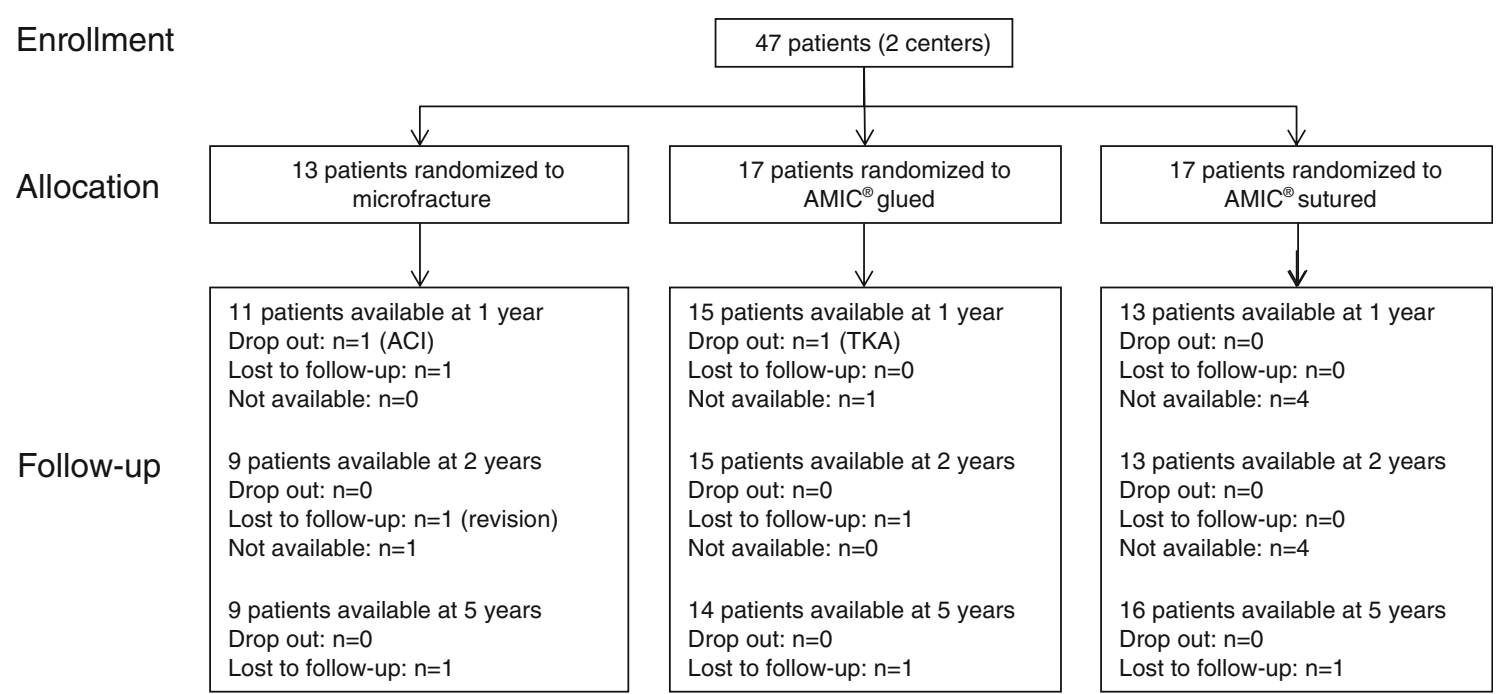

Fig. 2 Baseline demographics and stratification of the ITT population of the two centers continuing follow-up for five years

improving in both $\mathrm{AMIC}^{\circledR}$ treated groups, whereas a significant decrease was observed in the MFx group $(p=0.002$ $\mathrm{AMIC}^{\circledR}$ glued, $\mathrm{p}=0.01 \mathrm{AMIC}^{\circledR}$ sutured).

The Modified ICRS score for pain (Figs. 4 and 5) showed a significant decrease of pain for all groups. Baseline pain was 57 $\pm 22,46 \pm 20$, and $54 \pm 19$ for patients assigned to the MFx, the glued AMIC ${ }^{\circledR}$ and the sutured AMIC ${ }^{\circledR}$ groups, respectively. At one year post-operation pain decreased significantly to $15 \pm 17$ for MFx $(\mathrm{p}<0.001), 15 \pm 13(\mathrm{p}<0.001)$ for glued $\mathrm{AMIC}^{\circledR}$ and $16 \pm 15(\mathrm{p}<0.001)$ for sutured AMIC ${ }^{\circledR}$. After five years, both $\mathrm{AMIC}^{\circledR}$ treated patient groups still reported very low pain, whereas pain increased non-significantly in the MFx group.

\section{Functional scoring}

Almost all patients rated their status as abnormal before surgery (92.3\% in the MFx group, $100 \%$ in the $\mathrm{AMIC}^{\circledR}$ glued and $100 \%$ in the $\mathrm{AMIC}^{\circledR}$ sutured groups, respectively). This rating improved for all patient groups at one year, where only $11-23 \%$ of patients had an abnormal or severely abnormal status at two years. At five years, $66 \%$ of the patients in the MFx group were again in the abnormal ranking range and none of these patients were considered to have a normal knee, whereas in the AMIC groups, severe ranking was only reported by $6-7 \%$ of the patients.

Similarly, the objective functional status was abnormal or severely abnormal pre-operatively for about $80 \%$ of the patients in each group. After one year, functional improvement was noted in all groups, lowering the group of severely affected patients to $25-35 \%$ after one year. After two years, the proportion of abnormal or severely abnormal status was noted in 33\% of patients in the MFx group and $0-7 \%$ in the $\mathrm{AMIC}^{\circledR}$ treated groups. After five years, the abnormal/severely abnormal patient populations amounted to $66 \%$ in the MFx group and $0-7 \%$ in the AMIC $^{\circledR}$ groups. Finally, $90-100 \%$ of the AMIC $^{\circledR}$ treated patients had improved to a normal or nearly normal functional status, whichever assessment was made.

\section{MRI evaluation}

At one year post operation, 35-50\% of the patients had a defect filling of two thirds or more. Complete integration could be observed in $15-30 \%$ of patients in the different groups.
Table 1 Overview of the patient demographics and baseline characteristics (two centers)

\begin{tabular}{lllll}
\hline & Total & MFx & AMIC $^{\circledR}$ glued & AMIC $^{\circledR}$ sutured \\
\hline Patients (n) & 47 & 13 & 17 & 17 \\
$\varnothing$ Age ( $\pm \mathrm{SD})$ & $37 \pm 10$ & $40 \pm 6$ & $39 \pm 9$ & $34 \pm 11$ \\
$\varnothing$ Weight $(\mathrm{kg} \pm \mathrm{SD})$ & $84 \pm 12$ & $80 \pm 10$ & $87 \pm 10$ & $84 \pm 15$ \\
$\varnothing$ BMI $( \pm \mathrm{SD})$ & $26.8 \pm 3.9$ & $25.0 \pm 2.9$ & $27.6 \pm 4.0$ & $27.4 \pm 4.4$ \\
Sex (m/f) & $37 \mathrm{~m} / 10 \mathrm{f}$ & $10 \mathrm{~m} / 3 \mathrm{f}$ & $15 \mathrm{~m} / 2 \mathrm{f}$ & $12 \mathrm{~m} / 5 \mathrm{f}$ \\
Previous operation (yes) & 24 & 6 & 8 & 10 \\
$\varnothing$ Defect size after debridement $( \pm \mathrm{SD})$ & $3.6 \pm 1.6$ & $2.9 \pm 0.8$ & $3.9 \pm 1.1^{*}$ & $3.8 \pm 2.1$ \\
Meniscus revision (yes) & 15 & 6 & 4 & 5 \\
\hline
\end{tabular}

* significance versus MFx: $p=0.01$ 
Fig. 3 Modified Cincinnati score. Number of patients available at five years follow-up (n): Microfracture (9), AMIC glued $(14, p=0.002)$, and AMIC sutured $(16, \mathrm{p}=0.01) ; *$ significance versus Microfracture at five years
Modified Cincinnati Score

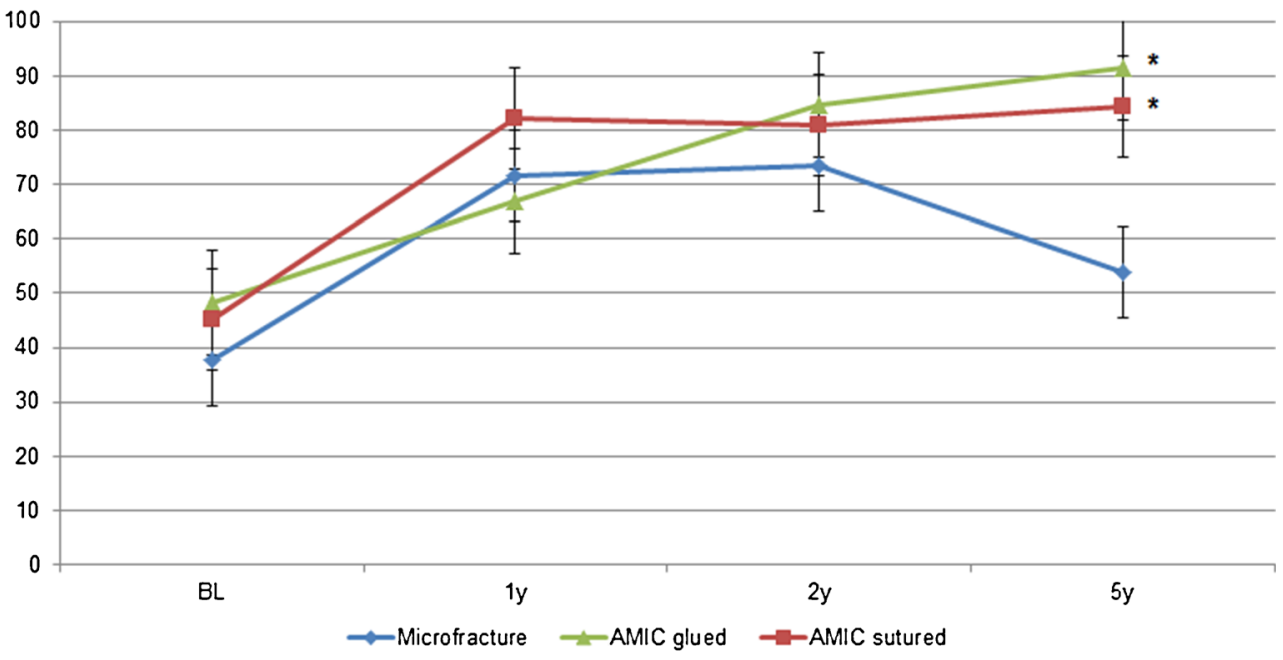

At two years, the defect filling was more complete in the $\mathrm{AMIC}^{\circledR}$ treated groups, where at least $60 \%$ of the patients had a defect filling of more than two-thirds. In the MFx group, only $25 \%$ of the patients achieved such filling.

At five years post operation, the defect filling was the lowest in the MFx group, versus both $\mathrm{AMIC}^{\circledR}$ treated groups (Table 2).

\section{Histological evaluation}

Biopsies were obtained at two years only in two patients, both belonging to the AMIC sutured group. Both showed the presence of a fibrocartilaginous matrix, without evidence of residual membrane material, and in one case cell cluster formation was observed in the deep zone of the repair tissue. Hyaline cartilage specific markers were identified, as Safranin-O, collagen-type I and II and a glycosaminoglycan. Both repair tissue were characterized as mostly fibrocartilagenous.

\section{Safety}

One patient treated with glued $\mathrm{AMIC}^{\circledR}$ received a joint replacement after one year and one patient with MFx received an ACI procedure after one year. For the complete study population, 13 adverse events were reported in nine patients. No serious adverse event related to the treatment was reported for any patient.

\section{Discussion}

AMIC $^{\circledR}$ combines MFx treatment with a collagen membrane (Chondro-Gide ${ }^{\circledR}$ ) and was developed to treat small- to mediumsized cartilage defects $\left(>2 \mathrm{~cm}^{2}\right)$. The hypothesis funding this RCT with $\mathrm{AMIC}^{\circledR}$ in focal cartilage defects of the knee was that the use of a covering membrane in an $\mathrm{AMIC}^{\circledR}$ procedure would result in sustained benefit compared to microfracturing alone at
Fig. 4 Modified ICRS scorepain. Number of patients available at five years follow-up (n): Microfracture (8), AMIC glued (13), and AMIC sutured (16)

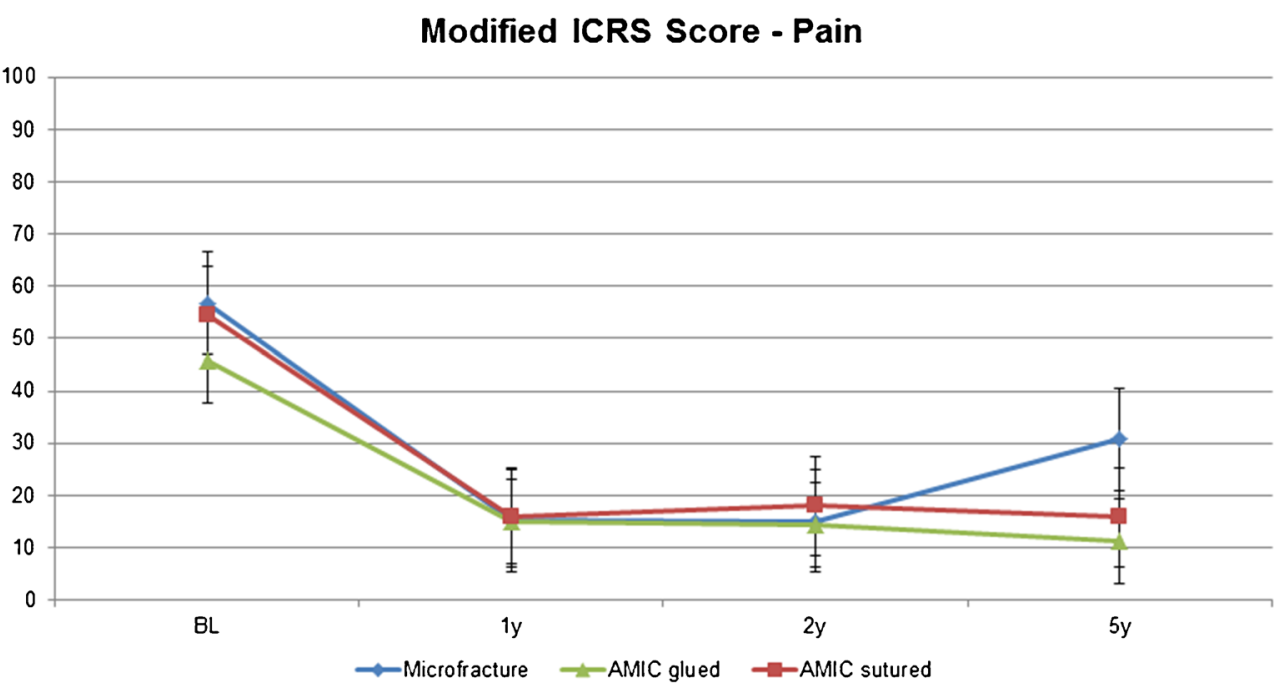




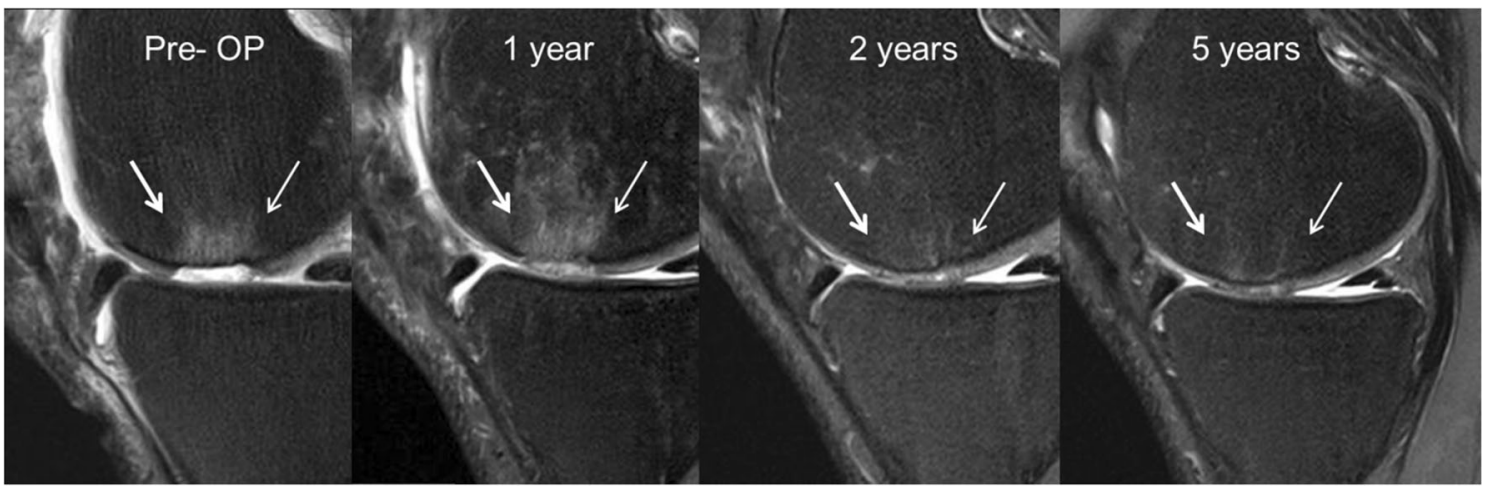

Fig. 5 Example of MRI (1.5 T) follow-up at one, two and five years (glued $\mathrm{AMIC}^{\circledR}$, medial femoral condyle): Proton density weighted sequence $(\mathrm{PDw})$ in sagittal orientation with defect filling almost

five years. This was confirmed by our results. After improvement for the first two years in all subgroups, a progressive and significant score degradation was observed in the MFx group, while all functional parameters remained stable for at least five years in the AMIC ${ }^{\circledR}$ groups. Both modes of ChondroGide ${ }^{\circledR}$ fixation resulted in similar mid-term clinical benefit. At two years and later, defect filling in MRI was notably more complete in the $\mathrm{AMIC}^{\circledR}$ treated groups (at least $60 \%$ of the complete $(20 \times 20 \mathrm{~mm}$, see arrow), surface remaining slightly uneven, good marginal integration, and repair tissue nearly isointense to adjacent genuine cartilage

patients had a defect filling of more than 2/3) compared to the MFx group with only $25 \%$ of such a filling. At five years the defect filling was the lowest in the MFx group.

Overall, our data are in agreement with the results of Gille et al. reporting a significant improvement in clinical outcomes in patients treated with $\mathrm{AMIC}^{\circledR}$, assessed by five different scores up to 36 months [22]. Similar results were found in a larger multicentre observational study including 57 patients

Table 2 MRI evaluation

\begin{tabular}{|c|c|c|c|c|c|c|c|c|c|c|}
\hline & & \multicolumn{3}{|l|}{ MFx } & \multicolumn{3}{|c|}{ Glued AMIC ${ }^{\circledR}$} & \multicolumn{3}{|c|}{ Sutured AMIC ${ }^{\circledR}$} \\
\hline & & $\begin{array}{l}1 \text { year } \\
(n=11)\end{array}$ & $\begin{array}{l}2 \text { year } \\
(n=6)\end{array}$ & $\begin{array}{l}5 \text { year } \\
(n=9)\end{array}$ & $\begin{array}{l}1 \text { year } \\
(n=16)\end{array}$ & $\begin{array}{l}2 \text { year } \\
(n=15)\end{array}$ & $\begin{array}{l}5 \text { year } \\
(n=11)\end{array}$ & $\begin{array}{l}1 \text { year } \\
(n=14)\end{array}$ & $\begin{array}{l}2 \text { year } \\
(n=14)\end{array}$ & $\begin{array}{l}5 \text { year } \\
(n=12)\end{array}$ \\
\hline \multirow[t]{5}{*}{ Defect filling } & none & 0 & 0 & 1 & 1 & 1 & 2 & 2 & 3 & 4 \\
\hline & $1 / 3$ & 3 & 2 & 4 & 0 & 3 & 2 & 1 & 2 & 1 \\
\hline & $1 / 3-2 / 3$ & 3 & 2 & 2 & 5 & 1 & 3 & 5 & 1 & 1 \\
\hline & $>2 / 3$ & 5 & 2 & 2 & 9 & 10 & 4 & 6 & 8 & 6 \\
\hline & not evaluable & 0 & 0 & 0 & 1 & 0 & 0 & 0 & 0 & 0 \\
\hline \multirow[t]{4}{*}{ Surface } & largely uneven & 4 & 3 & 5 & 2 & 2 & 4 & 4 & 3 & 3 \\
\hline & partially uneven & 4 & 1 & 3 & 11 & 6 & 3 & 6 & 4 & 4 \\
\hline & smooth & 3 & 3 & 0 & 2 & 6 & 2 & 2 & 4 & 1 \\
\hline & not evaluable & 0 & 0 & 1 & 1 & 1 & 2 & 2 & 3 & 4 \\
\hline \multirow[t]{4}{*}{ Integration } & $\begin{array}{l}\text { marginal gap up to } \\
50 \%\end{array}$ & 1 & 2 & 4 & 0 & 1 & 4 & 2 & 1 & 0 \\
\hline & marginal gap & 8 & 1 & 4 & 10 & 9 & 3 & 5 & 3 & 2 \\
\hline & complete & 1 & 4 & 0 & 5 & 4 & 2 & 4 & 6 & 5 \\
\hline & not evaluable & 1 & 0 & 1 & 1 & 1 & 2 & 3 & 4 & 5 \\
\hline \multirow{3}{*}{$\begin{array}{l}\text { Signal intensity of } \\
\text { defect cover }\end{array}$} & inhomogeneous & 8 & 3 & 7 & 7 & 5 & 7 & 7 & 5 & 7 \\
\hline & homogenous & 3 & 4 & 1 & 8 & 9 & 2 & 5 & 6 & 1 \\
\hline & not evaluable & 0 & 0 & 1 & 1 & 1 & 2 & 2 & 3 & 4 \\
\hline \multirow{5}{*}{$\begin{array}{l}\text { Bone marrow } \\
\text { lesion }\end{array}$} & massive $(>2 \mathrm{~cm})$ & 0 & 1 & 3 & 1 & 1 & 4 & 0 & 1 & 4 \\
\hline & $\begin{array}{l}\text { intermediate } \\
\quad(1-2 \mathrm{~cm})\end{array}$ & 5 & 1 & 3 & 4 & 6 & 3 & 4 & 6 & 4 \\
\hline & small $(<1 \mathrm{~cm})$ & 5 & 3 & 2 & 7 & 6 & 3 & 9 & 7 & 4 \\
\hline & none & 0 & 2 & 1 & 4 & 2 & 1 & 1 & 0 & 0 \\
\hline & not evaluable & 1 & 0 & 0 & 0 & 0 & 0 & 0 & 0 & 0 \\
\hline
\end{tabular}


with grade III or IV chondral lesions evaluated two-years post-operatively [23]. Pascarella et al. evaluated the results of AMIC $^{\circledR}$ using Pridie perforations instead of MFx, assessed up to 36 months with significant improvement in clinical scores and reduction of the defect area [24]. Similar results were shown for 17 patients with a larger mean defect size and $76 \%$ of the patients were satisfied or extremely satisfied [25]. Kusano et al. evaluated outcomes of 38 patients treated with $\mathrm{AMIC}^{\circledR}$ for full-thickness chondral and osteochondral defects of the femoral condyles and patella [26]. After a mean followup of 29 months, significant improvements in clinical outcome scores were noted where the largest improvements were seen in the osteochondral subgroup.

Discussion and justification of the study design is necessary for several reasons. When AMIC $^{\circledR}$ was developed, Chondro-Gide ${ }^{\circledR}$ was thought to be sutured to the defect site, as in ACI. However, since fixation with fibrin glue had been established for MACI, a third group — glued AMIC ${ }^{\circledR}$ — was added. Meanwhile, gluing is routinely carried out and has proven to be a feasible fixation technique. No different failure rate associated with the fixation mode of the membrane was seen in our study favoring the use of glue for fixation. In 2003, when the study was designed, contemporary classification and outcome scores for cartilage were used. Here the Outerbridge classification for defect grading and Modified Cincinnati, not specific for cartilage repair and the Modified ICRS score was chosen.

The inclusion/exclusion criteria for this study were very restrictive. It was extremely difficult to convince patients to participate, since they did not want to be treated randomized. Hence, recruitment was very slow and therefore centers with low activity had to be closed after their patients reached the two year follow-up. Though requested, not all patients did show for every controls as scheduled for personal reasons explaining the varying numbers at different follow-ups. The rather small resulting sample size of each group might therefore hide some of the nonsignificant differences observed in this study. Moreover, since patients did not agree to undergo biopsy as a routine, only two biopsies could be analyzed at two years. Therefore, the exclusive morphological cartilage repair assessment became based on MRI. In this study, MRI defect filling was more complete in the $\mathrm{AMIC}^{\circledR}$ groups at two and five years. In this context, two recent meta-analyses of de Windt et al. [27] and of Blackman et al. [28] pointed out that conclusive evidence to determine whether morphological MRI is reliable in predicting clinical outcome after cartilage repair is lacking. These reports also stated that no MRI classification has been shown to correlate with clinical outcomes after different types of cartilage repair. This was supported by the study of Shive et al., comparing in an RCT the BSTCarGel treatment with microfracture [29]. The authors were able to show a significantly better defect filling in the treated group versus MFx, whereas no clinical or functional difference could be established between the groups. Since the interpretation of cartilage structure from morphological MRI data is still debated and does not correlate with clinical outcomes, the clinical and functional scores were considered as the primary outcomes here.

Conflicting data have also been published regarding the durability of different cartilage repair strategies. Although some groups have reported mid- and long-term survival rates of approximately $75 \%$ after MFx [30], others have observed that good short-term results are not maintained in the longterm [5]. This was the case in the recently reported RCT, comparing MFx to MFx associated to BST-CarGel [29]. These authors did not find a difference in the clinical scoring and no impairment of the WOMAC score was detected between one and five years. They suggested that when performed properly, MFx can effectively improve pain and function despite the widely reported clinical outcome expectancy of two to three years. However, in this RCT, the mean lesion area was of 2.08 to $2.4 \mathrm{~cm}^{2}$ in the MFx or MFx + BST-CarGel groups respectively. This small lesion size may explain the five years of stable results observed in the MFx group.

To the best of our knowledge, to date, no randomized controlled studies have been published comparing $\mathrm{AMIC}^{\circledR}$ with other cartilage repair procedures. Data from our RCT confirm the general consensus of a progressive decrease of the microfracture benefit after two years. This finding is reflected in the literature, particularly when the lesion size was larger than $2 \mathrm{~cm}^{2}[6,31,32]$. Our mean lesion size was $3.6 \pm 1.6 \mathrm{~cm}^{2}$ representing mid-sized lesions and our findings in the MFx group can clearly prove progressive degradation after two years. No treatment-related adverse events were reported. Conversely, we can confirm that all clinical variables remained stable at least five years following surgery independent of which $\mathrm{AMIC}^{\circledR}$ procedure was used. Both modes of Chondro-Gide ${ }^{\circledR}$ fixation resulted in similar short-term and mid-term beneficial clinical outcomes.

As a conclusion, $\mathrm{AMIC}^{\circledR}$ is an effective cartilage repair procedure in the knee resulting in stable clinical results significantly better than the MFx group at five years.

Acknowledgements The clinical site investigators and their clinical research coordinators who contributed to the initial phases of the study and recruitment and follow-up for 2 years are sincerely acknowledged: Prof. P. Behrens, Universitätsklinikum Schleswig-Holstein, Lübeck; Dr. W. Zoch, Unfallklink Hannover; Prof. P. Niemeyer, Universitätsklinikum Freiburg; PD Dr. E. Basad, Universitätsklinikum Giessen; and Dr. H.R.W. Meyer, Orthopedikum Hamburg.

The authors would like to thank Holger Klöss (Geistlich Pharma AG, Switzerland) for the continued support during the study and the critical comments throughout the review process of the manuscript.

\section{Compliance with ethical standards}

Funding This study was funded by Geistlich Pharma AG, Wolhusen, Switzerland. 
Conflict of interests The authors declare that they have no conflict of interest.

Open Access This article is distributed under the terms of the Creative Commons Attribution 4.0 International License (http:// creativecommons.org/licenses/by/4.0/), which permits unrestricted use, distribution, and reproduction in any medium, provided you give appropriate credit to the original author(s) and the source, provide a link to the Creative Commons license, and indicate if changes were made.

\section{References}

1. Richter W (2009) Mesenchymal stem cells and cartilage in situ regeneration. J Intern Med 266(4):390-405

2. Smith GD, Knutsen G, Richardson JB (2005) A clinical review of cartilage repair techniques. J Bone Joint Surg (Br) 87(4):445-9

3. Peterson L, Vasiliadis HS, Brittberg M, Lindahl A (2010) Autologous chondrocyte implantation: a long-term follow-up. Am J Sports Med 38(6):1117-24

4. Steadman JR, Miller BS, Karas SG, Schlegel TF, Briggs KK, Hawkins RJ (2003) The microfracture in the treatment of fullthickness chondral lesions of the knee in National Football League players. J Knee Surg 16(2):83-6

5. Kreuz PC, Steinwachs MR, Erggelet C, Krause SJ, Konrad G, Uhl $M$ et al (2006) Results after microfracture of full-thickness chondral defects in different compartments in the knee. Osteoarthritis Cartilage 14(11):1119-25

6. Mithoefer K, McAdams T, Williams RJ, Kreuz PC, Mandelbaum BR (2009) Clinical efficacy of the microfracture technique for articular cartilage repair in the knee: an evidence-based systematic analysis. Am J Sports Med 37(10):2053-63

7. Behrens P (2005) Matrixgekoppelte Mikrofrakturierung. Arthroskopie 28:193-7

8. Gille J, Kunow J, Boisch L, Behrens P, Bos I, Hoffmann C et al (2010) Cell-laden and cell-free matrix-induced chondrogenesis versus microfracture for the treatment of articular cartilage defects: a histological and biomechanical study in sheep. Cartilage 1(1):29-42

9. Lee YH, Suzer F, Thermann H (2014) Autologous matrix-induced hondrogenesis in the knee: a review. Cartilage 5(3):145-53

10. Zhang C, Cai YZ, Lin XJ (2016) One-step cartilage repair technique as a next generation of cell therapy for cartilage defects: biological characteristics, preclinical application, surgical techniques, and clinical developments. Arthroscopy 32(7):1444-50

11. Outerbridge RE (1961) The etiology of chondromalacia patellae. JBone Joint Surg Br 11(43-B):752-7

12. Steadman JR, Rodkey WG, Briggs KK, Rodrigo JJ (1999) The microfracture technic in the management of complete cartilage defects in the knee joint. Orthopade 28(1):26-32

13. Anders S, Volz M, Frick H, Gellissen J (2013) A randomized, controlled trial comparing autologous matrix-induced chondrogenesis (AMIC) to microfracture: analysis of 1- and 2-Year follow-up data of 2 centers. Open Orthop J 7:133-43

14. Gooding CR, Bartlett W, Bentley G, Skinner JA, Carrington R, Flanagan A (2006) A prospective, randomised study comparing two techniques of autologous chondrocyte implantation for osteochondral defects in the knee: periosteum covered versus type I/III collagen covered. Knee 13(3):203-10

15. ICRS (2000) Cartilage Injury Evaluation Package

16. Marlovits S, Singer P, Zeller P, Mandl I, Haller J, Trattnig S (2006) Magnetic resonance observation of cartilage repair tissue (MOCART) for the evaluation of autologous chondrocyte transplantation: determination of interobserver variability and correlation to clinical outcome after 2 years. Eur J Radiol 57(1):16-23

17. Hunter DJ, Lo GH, Gale D, Grainger AJ, Guermazi A, Conaghan PG (2008) The reliability of a new scoring system for knee osteoarthritis MRI and the validity of bone marrow lesion assessment: BLOKS (Boston Leeds osteoarthritis knee score). Ann Rheum Dis 67(2):206-11

18. Peterfy CG, Guermazi A, Zaim S, Tirman PF, Miaux Y, White D et al (2004) Whole-organ magnetic resonance imaging score (WORMS) of the knee in osteoarthritis. Osteoarthritis Cartilage 12(3):177-90

19. Mainil-Varlet P, Aigner T, Brittberg M, Bullough P, Hollander A, Hunziker E, Kandel R, Nehrer S, Pritzker K, Roberts S, Stauffer E (2003) Histological assesment of cartilage repair: a Report by the Histology Endpoint Committee of the International Cartilage Repair Society (ICRS). J Bone Joint Surg Am 85-A(Suppl 2):45-57

20. Brunner E, Langer F (2000) Nonparametric analysis of ordered categorical data in designs with longitudinal observations and small sample sizes. Biom J 42(6):663-75

21. R Development Core Team (2008) R: A language and environment for statistical computing. R Foundation for Statistical Computing, Vienna, Austria

22. Gille J, Schuseil E, Wimmer J, Gellissen J, Schulz AP, Behrens P (2010) Mid-term results of Autologous Matrix-Induced Chondrogenesis for treatment of focal cartilage defects in the knee. Knee Surg Sports Traumatol Arthrosc 18(11):1456-64

23. Gille J, Behrens P, Volpi P, de Girolamo L, Reiss E, Zoch W, Anders $S$ (2013) Outcome of autologous matrix induced chondrogenesis (AMIC) in cartilage knee surgery: data of the AMIC registry. Archives Orthop Trauma Surg 133(1):87-93

24. Pascarella A, Ciatti R, Pascarella F, Latte C, Di Salvatore MG, Liguori L et al (2010) Treatment of articular cartilage lesions of the knee joint using a modified AMIC technique. Knee Surg Sports Traumatol Arthrosc 18(4):509-13

25. Schiavone Panni A, Cerciello S, Vasso M (2011) The manangement of knee cartilage defects with modified amic technique: preliminary results. Int J Immunopathol Pharmacol 24(1 Suppl 2):149-52

26. Kusano T, Jakob RP, Gautier E, Magnussen RA, Hoogewoud H, Jacobi M (2012) Treatment of isolated chondral and osteochondral defects in the knee by autologous matrix-induced chondrogenesis (AMIC). Knee Surg Sports Traumatol Arthrosc 20(10):2109-15

27. de Windt TS, Welsch GH, Brittberg M, Vonk LA, Marlovits S, Trattnig $S$ et al (2013) Is magnetic resonance imaging reliable in predicting clinical outcome after articular cartilage repair of the knee? A systematic review and meta-analysis. Am J Sports Med 41(7):1695-702

28. Blackman AJ, Smith MV, Flanigan DC, Matava MJ, Wright RW, Brophy RH (2013) Correlation between magnetic resonance imaging and clinical outcomes after cartilage repair surgery in the knee: a systematic review and meta-analysis. Am J Sports Med 41(6): 1426-34

29. Shive MS, Stanish WD, McCormack R, Forriol F, Mohtadi N, Pelet $\mathrm{S}$ et al (2015) BST-CarGel(R) Treatment maintains cartilage repair superiority over microfracture at 5 years in a multicenter randomized controlled trial. Cartilage 6(2):62-72

30. Steadman JR, Briggs KK, Rodrigo JJ, Kocher MS, Gill TJ, Rodkey WG (2003) Outcomes of microfracture for traumatic chondral defects of the knee: average 11-year follow-up. Arthroscopy 19(5): 477-84

31. Goyal D, Keyhani S, Lee EH, Hui JH (2013) Evidence-based status of microfracture technique: a systematic review of level I and II studies. Arthroscopy 29(9):1579-88

32. Solheim E, Hegna J, Inderhaug E, Oyen J, Harlem T, Strand T (2016) Results at 10-14 years after microfracture treatment of articular cartilage defects in the knee. Knee Surg Sports Traumatol Arthrosc 24(5):1587-93 